\title{
Application of Yoga in Recovery Training of Middle and Long Distance Running
}

\author{
Devanshu Ojha \\ Department of Yoga, SAI NSNIS, Patiala, India \\ devanshuojha23@gmail.com
}

\begin{abstract}
Middle-distance running events are track races longer than sprints, up to 3000 meters. The standard middle distances are the 800 meters, 1500 meters, and mile run, although the 3000 meters may also be classified as a middle-distance event. The $1500 \mathrm{~m}$ came about as a result of running 3+3/4 laps of a $400 \mathrm{~m}$ outdoor track or 7+1/2 laps of a $200 \mathrm{~m}$ indoor track, which were commonplace in continental Europe in the 20th century. In modern competitive sports, the psychological preparation of a team is as important as teaching them the different skills of a game with scientific methods. These days, the teams are prepared not only to play but to win the games. And for winning the games, it is not only the proficiency in the skills which matters but also the spirit and attitude of the players with which they play and health-related fitness requires desirable levels of cardiovascular fitness, percentage body fat, flexibility, and endurance. These help to prevent the incidence and severity of degenerative types of disease and increase work efficiency. Cardiovascular fitness refers to the efficiency of the lungs and heart. Muscular strength and endurance are the capacity of the muscles to work against the resistance for a longer time. Flexibility is the ability to move a joint freely through its complete range of movement. Percentage of body fat refers to the proportion of an individual's total body fat. Earlier research showed that Yoga is the best way for balance in physical and mental fitness and it also increases players' performance in middle-distance runners through improved motor ability. A hypothesis has been constructed to meet the objectives of the proposed research work showing the significant effect of yoga practices to enhance the performance of middle-distance runners in athletics. This work was experimental-based research. The proposed research is on samples were randomly selected boys from JN Stadium. New Delhi. The selected age groups of the subjects were from 18 to 25 years. In each group, 30 subjects were selected. In all, 60 subjects were tested initially and the same 60 subjects were tested finally after two months with the training imparted on them. After comparing the mean and standard deviation it is observed that Yoga intervention was found useful to enhance the performance of middle-distance runners in athletics.
\end{abstract}

Keywords: Yoga, Athletics, Middle-distance runner, Pranayama, Meditation

\section{Introduction}

Yoga is more than a physical exercise. Yoga means "union" and leads to an integration of mind and body. It facilitates change based on the principles of reflection, integrity and awakening. Central to the practice is vision and transformation. Hatha yoga is traditionally made up of asana (posture) practice, pranayama and bandha/mudra work. Often the asana practice is referred to as hatha yoga and there are now a multitude of different styles of hatha yoga being taught.

Yoga is a physical, mental, and spiritual practice or discipline which originated in India. There is a broad variety of schools, practices, and goals in Hinduism, Buddhism and Jainism. Among the most well-known types of yoga are hatha yoga and Raja yoga.

\section{Sport of athletics:}

The sport of athletics is an exclusive collection of sporting events that involve competitive running, jumping, throwing, and walking. The most common types of athletics competitions are track and field, road running, cross country running, and race walking.

Middle distance running Events:-

Middle-distance running events are track races longer than sprints, up to 3000 metres. The standard middle distances are the 800 metres, 1500 metres and mile run, although the 3000 metres may also be classified as a middle-distance event. The $1500 \mathrm{~m}$ came about as a result of running $3+3 / 4$ laps of a $400 \mathrm{~m}$ outdoor track or $7+1 / 2$ laps of a $200 \mathrm{~m}$ indoor track, which were commonplace in continental Europe in the 20th century.

\section{Statement of the Problem}

The present research problem has been stated as: "Effect of Yoga to enhance the performance of middle distance runners in athletics".

\section{Objectives of the Study}

Objectives: The main objective of the study will be-

To study the effect of Yoga: Enhance the performance of middle distance runners in athletics".

\section{Hypothesis of the Study}

The following research hypothesis has been constructed to meet the objectives of proposed research work:

There would be significant effect of yoga to enhance the performance of middle distance runners in athletics.

\section{Research Methodology}

The proposed research work is an experimental based research.

\section{Research Sample}

The proposed research is on sample of 60 boys was taken randomly from JN Stadium New Delhi under the guidance of Avneesh Sir (Athletics Coach, SAI). The selected age groups of the subjects were from 18 to 25 years. 


\section{Dependent Variables and Tools Used}

Before and after experiment following variables were assessed considering standard tests.

\section{Selected Variables and Tools used}

\begin{tabular}{|c|c|c|c|}
\hline $\begin{array}{c}\text { Sr. } \\
\text { No. }\end{array}$ & Test Name & Tools Used & $\begin{array}{c}\text { Measurement } \\
\text { units }\end{array}$ \\
\hline 1 & Flexibility & Sit \& Reach & $\mathrm{cm}$. \\
\hline 2 & Cardiovascular Endurance & 1 Mile Run & Min Sec. \\
\hline 3 & Agility & Shuttle Run & Min Sec. \\
\hline 4. & Strength and anaerobic power & Vertical Jump & Inches \\
\hline
\end{tabular}

\section{Study Procedure}

In all, 60 subjects were tested initially and the same 60 subjects were tested finally after two months with training imparted on them. We divided subjects equally in 2 groups, Here group B is Controlled group and A is Experimental. After the pre test was over, all the subjects of Group A were exposed to a practice of Speed, Agility, Flexibility and Endurance (Pull Up, Sit up and Standing Broad Jump) and Group B participated in the training of Speed, Agility, Flexibility and Endurance (Pull Up, Sit up and Standing Broad Jump) followed by Yoga. . This indicates that the subjects of both the groups were participated in training, which is common. This common training was imparted for both the groups for $1 \mathrm{hr}$. daily in the evening except Mondays and holidays. However, after completion of $1 \mathrm{hr}$. training, whereas Group A underwent 30 minutes of yoga practices. Thus, duration of training / day was 90 minutes in the evening for 6 days in a week for a total period of 8 weeks.

\section{Description of Training Interventions}

The Static Stretching method is a simple method for increasing range of movement around joints. Where muscle groups are tight (shortened), they can constrain full movement range, especially after intensive activity or training. Slowly stretching the muscle through to its full range and holding the position returns the muscle to it's full length. The method requires a segment to be moved slowly and gently to the limit of its full movement and then the position is held for at least thirty seconds and may be held for up to a minute. Following static stretches were included as part of training for participants of Group A subject: Bhujangasana (The Cobra posture), Ardha-Shalabhasana (Half Locust Pose), Ardhhalasana (Half Plough Pose), Vakrasana (Twisting pose), Chakrasana (Wheel Pose), Deep Relaxation Technique, Kapalabhati Kriya, Anuloma-Viloma Pranayama, Cooling Pranayama-Beak Breath, Ujjayi Pranayama: Ocean Sounding Breath, Bhramri Pranayama, Om Chanting.

\begin{tabular}{|c|c|c|c|c|}
\hline \multirow{2}{*}{ Statically model for presentation of data } \\
\cline { 2 - 5 } Variables (A) & $\begin{array}{r}|c| \\
\text { Yoga Training Group } \\
(\mathrm{B})\end{array}$ & $\begin{array}{r}\text { Control Group } \\
\text { (C) }\end{array}$ \\
\cline { 2 - 5 } & B1 (pre) & B2 (post) & C1 (pre) & C2 (post) \\
\hline Flexibility (A1) & (A1 B1) & (A1 B2) & (A1 C1) & (A1 C2) \\
\hline $\begin{array}{c}\text { Cardiovascular } \\
\text { Endurance (A2) }\end{array}$ & (A2 B1) & (A2 B2) & (A2 C1) & (A2 C2) \\
\hline Agility (A3) & (A3 B1) & (A3 B2) & (A3 C1) & (A3 C2) \\
\hline $\begin{array}{c}\text { Strength and anaerobic } \\
\text { power (A4) }\end{array}$ & (A4 B1) & (A4 B2) & (A4 C1) & (A4 C2) \\
\hline
\end{tabular}

\section{Summary / Conclusion}

For Flexibility (A1), indicates that the pre-test performance scores of the Athletics plus Yoga training group and Athletics group were $10.72(\mathrm{SD}=2.05)$ and $10.88(\mathrm{SD}=2.03)$ respectively. This result indicates that the pre test means of Athletics plus Yoga training group and Athletics group in Flexibility test were more or less similar.

However, post-test performance scores of the Athletics plus Yoga training group and Athletics group were 14.12 $(\mathrm{SD}=2.79)$ and $10.6 \quad(\mathrm{SD}=2$.$) respectively. This result$ indicates that the post-test means of both the Yoga training group and Athletics group in Flexibility were different.

For Cardiovascular Endurance (A2) indicates that the pretest performance scores of the Athletics plus Yoga training group and athletics group were $6.97(\mathrm{SD}=0.69)$ and 7.01 $(\mathrm{SD}=0.65)$ respectively. This result dictates that the pre-test means of Athletics plus Yoga training group and Athletics group in Cardiovascular Endurance test were more or less similar.

However, post-test performance scores of the Athletics plus Yoga training group and Athletics group were 6.40 $(\mathrm{SD}=0.66)$ and $7.02(\mathrm{SD}=0.67)$ respectively. This result indicates that the post-test means of both the Athletics plus Yoga training group and Athletics group in Cardiovascular Endurance were different.

For Agility (A3), indicates that the pre-test performance scores of the Athletics plus Yoga training group and Athletics group were $110.36(\mathrm{SD}=10.02)$ and 110.23 $(\mathrm{SD}=7.66)$ respectively. This result indicates that the pre test means of Athletics plus Yoga training group and Athletics group in Shuttle Run were more or less similar.

However, post-test performance scores of the Athletics plus Yoga training group and Athletics group were 108.80 $(\mathrm{SD}=16.15)$ and $110.09(\mathrm{SD}=7.53)$ respectively. This result indicates that the post-test means of both the Athletics plus Yoga training group and Athletics group in shuttle run were different.

For, Strength and anaerobic power (A4) indicates that the pre-test performance scores of the Athletics plus Yoga training group and Athletics group were 35.88 ( $\mathrm{SD}=5.26)$ and $35.72(\mathrm{SD}=3.01)$ respectively. This result indicates that the pre-test means of Athletics plus Yoga \& Pranayama training group and Athletics group in Strength and anaerobic power test were more or less similar.

However, post-test performance scores of the Athletics plus Yoga training group and Athletics group were 40.36 $(\mathrm{SD}=4.94)$ and $35.36(\mathrm{SD}=3.24)$ respectively. This result indicates that the post-test means of the Athletics plus Yoga training group and Athletics group in Strength and anaerobic power were different

On the basis of overall result and discussion as presented above, this study indicates that Yoga intervention was found useful to enhance the performance of middle distance runners in athletics. 


\section{References}

[1] Ackland T., Blanksby B., Landers G and Smith D.1998. Anthropometric correlates with performance among world championship triatheletes. Paper present in Australian conferences of science and medicine in sport, Adelaide.

[2] Adiputra N., 1988. Body composition and somatotype characteristics of Balinese dancer, MKU, Indonesia, 59, 14-18,

[3] Agbonjinmi A. P., 1998. Measures of Body, Body composition and Physical fitness of Female College Athletes. Jour. Of Phy. Edn. \& Sport Sci., 85.

[4] Almeida Tania Abreu de and Soares Eliane Abreu (2003) " Nutritional and anthropometric profile of adolescent volleyball athletes" Rev Bras Med Esporte vol.9 no.4, July/Aug. 2003.

[5] Bale P., 1980. The relationship of physique and body composition to strength in a group of physical education students. British Journal of Sports Medicine, 14 (4): 193-198.

[6] Bale P., 1986. A review of the physique and performance qualities characteristics of games players in specific positions on the field of play. Journal of Sports Medicine and Physical Fitness, 26 (2): 109-122.

[7] Behnke A. R. "Exercise Physiology" New York Academic Press, 1968. Behnke A. R. and Royce J., 1996. Body size, shape and composition of general types of athletes. J. Sports Med. and Phys. Fitness, 675.

[8] Behnke R. S. "Kinetic Anatomy" Human Publication, U. S. A., 2001. Bell W., 1973. Distribution of skin folds and differences in body proportion in young adult rugby players, J. Sports Med. Phys. Fit.13: 69.

[9] Beunen G., Claessens A., Lefevre J., Ostyn M., Renson R. and Simons, J., 1987.

[10] Somatotype as related to age at peak velocity and to peak velocity in height, weight an dstatic strength in boys. Human Biology, 59, 641-655.

[11] Biswas, Ashok Kumar.1998. Performance variables of different level Indian volley Ball Players LNIPE, Gwalior. 